\title{
Doğal Atık Malzemelerle Yeni NBR Bazlı Bileşiklerin Hazırlanması ve Karakterizasyonu
}

\section{Preparing and Characterizing New NBR-Based Compounds with Natural Waste Materials}

\author{
Şaban Bülbül $1^{*}$ \\ Geliş / Received: 13/05/2019 \\ Revize / Revised: 11/07/2019 \\ Kabul / Accepted: 11/07/2019
}

$\ddot{O}$

z- Bu çalışmada, Nitril-Butadien Kauçuğu (NBR) esasılı Genel (FKK0) bir referans kauçuk bileşiği içerisine, karbürize edilmiş findık kabuğu külünden (FKK) \% 0- \% 10- \% 15 ve \% 20 oranlarında ilave edilerek, 4 faklı bileşik hazırlanmıştır. Vulkanizasyon sonrasında bileşiklerin sertlik, yoğunluk, kopma dayanımı, kopma uzaması, yırtılma dayanımı ve çaprazbağ yoğunlukları ölçülmüştür. Çaprazbağ yoğunluğunun mekanik özellikler üzerine etkileri değerlendirilmiştir. Karbürize edilmiş findıkkabuğu külü ilave edilen bileşiklerin özellikleri, hem kendi aralarında hem de FKK0 bileşiğiyle karşılaştırılmıştır. Karbürize edilmiş findıkkabuğu külü, bileşiklerin maliyetini önemli ölçüde düşürmüştür. Artan çaprazbağ yoğunluğu ile bileşiklerin sertliğinde artş̧a neden olmakla birlikte, kopma dayanımı ve kopma uzamasında avantaj sağladığı görülmüş̧tür. Artan findıkkabuğu külünün yoğunluğu arttırdığı tespit edilmiştir. Kırık yüzey morfolojilerinin belirlenmesi amacıyla, bileşiklerin kopma yüzeyleri Taramalı Elektron Mikroskobu (SEM) ile karakterize edilmiştir. SEM görüntüleri incelendiğinde dolgu miktarını artmasıyla kauçuk matris içerisindeki dağılımının homojenliğin bozulduğu da görülmüştür.

Anahtar Kelimeler- NBR, Fındık Kabuğu Külü, Mekanik Özellikler

bstract- In this study, carbonized nutshell ash (NSA) was added at ratios of $0,10,15$, and $20 \%$ into a general (FKK0) nitrile- butadiene rubber (NBR) -based reference rubber compound and four compounds were prepared. After the vulcanization, the hardness, density, tensile strength, elongation at rupture, tear strength, and cross-link densities of the compounds were measured. The effects of the cross-link density on mechanical properties were evaluated. The properties of the compound with carbonized nutshell addition were compared to each other as well as with the FKK0 compound. The carbonized nutshell ash considerably decreased the costs of the compounds. While the increasing cross-link density caused an increase in hardness of the compounds, it provided an advantage for tensile strength and elongation at rupture. It was found that increasing nutshell ash increased the density. The compounds were characterized by a scanning electron microscope (SEM) in order to determine the fracture surface morphologies. When the SEM images were examined, it was observed that as a result of increasing amount of the filler, the homogeneity of the distribution within the rubber matrix observed.

Keywords- NBR, Nutshell Ash, Mechanical Properties

\footnotetext{
1*Sorumlu yazar iletișim: sabanbulbul@erbakan.edu.tr (https://orcid.org/0000-0002-9268-1469) Makine Mühendisliği, Necmettin Erbakan Üniversitesi, Konya, TÜRKIYE
} 


\section{I.GİRIŞ}

Teknolojinin gelişmesi, mevcut malzemelerin yetersizliğini ortaya çıkarmış ve yeni bileşiklerin, yeni karışımların ve yeni alaşımların araştırılmasını zorunlu hale getirmiştir. Polimer malzemelerin sağlık, uzay ve savunma sanayisinde, ayakkabı ve birçok alanda kullanılmasıyla birlikte kauçukların kullanımı dünya üzerinde artmıştır.

Geçmişte yapılan çalışmalar genellikle doğal kauçuk üzerine yapılmıştır. Daha sonra sentetik kauçukların üretilmesi ve endüstride kullanılmaya başlaması ile birlikte Stiren Butadien Kauçuk (SBR) ve Nitril-Butadien Kauçuğu (NBR) dünya literatüründe yerini almıştır. Ayakkabı tabanları başta olmak üzere bu malzemeler, araç lastikleri, cam silecekleri, oyuncaklar, su boruları ve sızdırmazlık elamanları (conta vb) gibi birçok sektörde ana malzeme olarak kullanılmaktadırlar.

Sentetik kauçuklardaki kullanımın artması ile birlikte ayakkabı dış tabanlarında aranılan bazı özelikleri de ön plana çıkarmıştır. Bunlar; hafiflik, esneklik, boyut kararlılığı, kopma dayanımı ve aşınmaya karşı dirençli olmasıdır. Özellikle NBR kauçuğu akrilonitril monomerlerinin kopolimerizasyonu ile elde edilir. Bu grup kauçukların polar özellik sağlayarak yağlara, solventlere ve mekanik aşındırıcılara karşı aşınma dayanımları yükselmektedir [1]. Bu sebepten ayakkabı dış tabanlarında kullanılmasının araştırılması gerekmektedir. NBR ve diğer kauçuklu bileşiklerden elde edilecek ürünün gerektirdiği özelliklere sahip olabilmesi için işlenme sırasında çok sayıda ve değişik özelliklere sahip dolgu ve katkı malzemeleri ilave edilmektedir [2]. Ayrıca kauçuk hamuruna ilave edilen dolgu malzemelerinin başında karbon siyahları gelmektedir. Fakat petrol fiyatlarının istikrasız olmasından dolayı organik ve inorganik malzemelerin dolgu olarak kullanılmasına önem verilmiştir [3,4]. Literatür çalışmalarına bakıldığında cam küre, pirinç kabuğu, wollastonit, mika tozu, zamk, karbon siyahı, fosfat, nanokil, silika, kalsit, yüksek fırın baca tozu, rejenere kauçuk, odun külü ve nano kalsiyum karbonat v.b. gibi birbirlerinden farklı dolguların kauçuk bileşiklerine ilave edilerek kullanıldığı dikkat çekmektedir [5-15]. Bilim insanlarının farklı dolgular kullanarak bileşiklerin mekanik ve fiziksel özeliklerini geliştirme adına yaptıkları birçok çalışma vardır bunlardan bazıları şu şekildedir;

Wang ve ark. Stiren-Butadien Kauçuk (SBR) matrisli bir kauçuk hamuruna belirli oranlarda Grafen Oksit (GO) ilave etmişler ve bunun neticesinde çapraz bağ yoğunluğunun mekanik özellikler üzerindeki etkisi belirlemek amacıyla bir araştırma yapmışlardır. GO'nun sadece etkili bir takviye dolgu maddesi olarak işlev yapmadığını, aynı zamanda SBR matrisli bileşiğin kovalat çapraz bağ yoğunluğunu ve mekanik özellikleri artırdığını ortaya koymuşlardır [16]. Bülbül ve Büyük'ün yaptıkları bir çalışmada, SBR matrisli kauçuklu bileşiklerine dolgu malzemeleri olarak farklı oranlarda kullanılan ceviz kabuğu külü ilave ederek mekanik özelliklerindeki değişimi incelemişlerdir. SBR hamuruna ilave edilen ceviz kabuğu külünün ilave edilme oranının artmasıyla, sertliğin ve yoğunluğun artığı kopma dayanımında ve \% birim uzamada azalma olduğunu fakat test sonuçlarının ISO standartlarında istenilen değerleri karşıladığını rapor etmişlerdir [17]. Kauçuk malzeme üzerine yapılan bir diğer çalışmada ise Akçakale N. karbürize edilmiş pirinç kabuğu toz ilavesinin SBR/Sırt Kauçuk matrisli bileşiğine ilavesinin mekanik özellikleri üzerine etkilerini araştırmıştır. Bileşiklere ilave edilen karbürize edilmiş pirinç kabuğu toz oranı artıkça, bileşiklerin sertlik, yoğunluk ve aşınma gibi özelliklerde artış olduğunu, kopma-yırtılma dayanımlarında ve \% uzama miktarında azalma olduğunu belirtmiştir [18]. Mekanik özellikleri araştırmak için (Nano-CaCO3) ve nano- kilin dolgu olarak kullanıldığı bir çalışmada; Doğal kauçuk (NR) matrisli bir bileşiğe ilave edilen kalsiyum karbonat oranı arttıkça çekme kuvveti ve birim uzamayı olumlu yönde etkilediğini vurgulamışlardır. Aynı çalışmada nano kilin ilave oranı arttıkça çekme kuvvetinin arttığını birim uzamanın ise azaldığını bunun yanında her iki dolgunun sertliği arttırdığı görülmüştür [19].

Dünyadaki en önemli fındık üretim merkezlerinde biri olan Türkiye'de fındık özellikle Karadeniz bölgesinde yetiştirilmektedir. Son yıllarda fındık ve fındık yağı üretimindeki artışın Türkiye'deki findıkkabuğu atık miktarının da artmasına sebep olmuştur [20]. Bu çalışmanın amacı karbürüze edilmiş fındık kabuk külünün kauçuk hamurlarında kullanılabilecek bir dolgu malzemesi olduğunu göstermek, benzer çalışmalara 1 şık tutabilmektir. Ayrıca yerli ve milli dolgular sayesinde dışa bağımlılığı azaltmak, ekonomiyi güçlendirmek ve bu sayede rekabet gücünü artırmaktır.

\section{II.MALZEME VE METOT}

Bu çalışmada kullanılan, NBR kauçuğu, dolgu ve katkı malzemelerinin tümü LBS Bileşim ve Laboratuvar Teknolojileri LTD.ŞTİ. Türkiye, firmasından temin edilmiştir. Fındıkkabuğu ise Giresun Tirebolu'da findık üreticiliği yapan Osman ÇAVUŞOĞLU tarafından ücretsiz olarak temin edilmiştir. Çalışmada kullanılan fındıkkabuklarının homojen bir şekilde karbürize olabilmesi için kırma makinesinden geçirerek 2 mm boyutlarında toz haline getirilmiştir. Toz haline getirilen findıkkabukları, Nevola marka tav fırınında $500{ }^{\circ} \mathrm{C}$ de, özel bir seramik 
pota içerisinde 1 saat yakılarak karbürize edilmiştir. Yakma sonucu elde edilen FFK tamamen soğuduktan sonra, 11000 devir/dk hızla çalışan çelik gövdeli Süper Mikser marka SM 132 model bir öğütücü yardımıyla tane boyutları küçültülmüştür $(25 \mu \mathrm{m})$.

NBR ve dolgu malzemeleri laboratuvar tipi banburide (Güncanlar marka) $60 \mathrm{rpm}$ hizda ve $60{ }^{\circ} \mathrm{C}$ 'de 10 $\mathrm{dk}$ boyunca karıştırılmıştır. Hamur 24 saat şartlandırıldıktan sonra laboratuvar tipi iki silindirli açık karıştırıcıda $80{ }^{\circ} \mathrm{C}$ 'de ve $40 \mathrm{rpm}$ hızda, 5 dakika boyunca karıştırılmış, sonrasında kütlece, \% 0, 10, 15 ve 20 oranlarında FFK ilave edilerek 5 dakika daha karıştırma işlemine devam edilmiştir. Son olarak hamura yumuşatıcılar, aktivatörler, hızlandırıcılar ve kükürt ilave edilerek 2 dakika boyunca karıştırılmış ve karıştırma işlemi tamamlanmıştır. Hazırlanan hamur bileşimleri Tablo 1'de verilmiştir.

Tablo 1. Kauçuk hamurunun \% bileşimi.

\begin{tabular}{lcccc}
\hline Bileşikler & \multicolumn{3}{c}{ Numunelerin isimleri } \\
\cline { 2 - 5 } & FKKO & FFK10 & FFK15 & F FK20 \\
& & \multicolumn{2}{c}{ \% oranı } \\
\hline NBR 1502 & 100 & 100 & 100 & 100 \\
Karabon siyahı & 35 & 35 & 35 & 35 \\
Kalsit (CaCO 3 ) & 25 & 25 & 25 & 25 \\
Aromatik Yağ & 7.5 & 7.5 & 7.5 & 7.5 \\
Aktif Çinko & 3.5 & 3.5 & 3.5 & 3.5 \\
Reçine & 2 & 2 & 2 & 2 \\
Dibenzothiazole disulfide (DM) & 2 & 2 & 2 & 2 \\
Ozonfax & 1 & 1 & 1 & 1 \\
PEK 4010 & 1 & 1 & 1 & 1 \\
Stearik Asit & 1 & 1 & 1 & 1 \\
Diphenyl guanidine (DPG) & 1 & 1 & 1 & 1 \\
Kükürt & 2 & 2 & 2 & 2 \\
FFK (Fındık Kabuğu Külü) & 0 & 10 & 15 & 20 \\
\hline
\end{tabular}

İnce levha haline getirilen çiğ kauçuk hamuru küçük parçalar halinde kesilerek, yapılacak test standartlarına uygun şekilde tasarlanmış sıkıştırılabilen bir kalıp içerisine yerleştirilerek, $160{ }^{\circ} \mathrm{C}$ sıcaklıkta ve 16 $\mathrm{MPa}$ basınç altında, 6 dakika boyunca baskı işlemi yapılmış ve kauçuk hamuru vulkanize edilmiştir.

Kauçukların çaprazbağ yoğunlukları temelde Flory-Rehner eşitliği olarak bilinen denge hacim şişme eşitliği kullanılarak hesaplanmıştır. Bu yöntem kauçukların uygun bir çözücü içerisinde şişirilmesi prensibine dayanır. Deney numuneleri klorofrom ortamında 72 saat süre ile bekletilmiş ve kauçuğun çözücü içerisindeki şişme oranına bağlı olarak çaprazbağ yoğunluğu Flory-Rehner eşitliğinden (Eşitlik-1) yararlanılarak hesaplanmıştır [21].

$$
V_{e}=\frac{-\left[\ln \left(1-V_{2}\right)+V_{2}+\chi V_{2}^{2}\right]}{V_{s}\left[V_{2}^{1 / 3}-\frac{V_{2}}{2}\right]}
$$

Burada,

$\mathrm{V}_{\mathrm{e}}$ : Çaprazbağ yoğunluğu $\left(\mathrm{mol} / \mathrm{cm}^{3}\right)$

$\mathrm{V}_{2}$ : Şişmiş örneğin hacim fraksiyonu

$\mathrm{V}_{\mathrm{s}}$ : Çözücünün molar hacmi $\left(\mathrm{cm}^{3} / \mathrm{mol}\right)$

ఒ: Polimer - çözücü etkileşim parametresidir.

$\mathrm{Bu}$ çalışmada bileşiklerin sertlikleri ISO 868 'e göre Affri Commerciale marka AFFRI 3001 model durometrede Shore A türünden ölçülmüştür. Bileşiklerin yoğunluk ölçümleri ise Arşimet prensibine göre ISO 2781 uyarınca yapılmış, referans sıvı olarak saf su kullanılmıştır. Çekme testi ISO 37-1 standardına göre Tinius marka H25KS model çekme cihazında, $10 \mathrm{~mm} / \mathrm{s}$ çekme hızında gerçekleştirilmiştir. Bileşiklerden alınan numune 
örneklerinin yırtılma testi ISO 34-1 standardına uygun olarak, Zwick Line Z2,5 marka çekme test cihazında gerçekleştirilmiştir.

Kopma testi sonrası numunelerin kopan yüzeylerinin morfolojileri, Zeiss Ultra/Plus taramalı elektron mikroskobu (SEM) kullanılarak incelenmiştir. Numunelerin kopan yüzeylerinin, iletkenliğini artırmak için $5 \mathrm{~nm}$ kalınlığında saf altınla kaplanmıştır [22]. Mikro-yapı görüntülerinin incelenmesi sırasında, mikroskobun çalışma voltaj1 $20 \mathrm{kV}$ olarak seçilmiştir.

\section{SONUÇLAR VE TARTIŞMA}

NBR 1502 matrisli bileşiklerin çaprazbağ yoğunlukları, içerdiği FKK miktarına bağlı olarak Şekil 1'de verilmiştir. Bileşiklerin çaprazbağ yoğunluğunun artan FKK ile birlikte sistematik şekilde arttığı görülmektedir. Elde edilen en yüksek çaprazbağ yoğunluğu FKK20 bileşiği için 139,13x10 $\mathrm{mol} / \mathrm{cm}^{3}$ 'tür. Referans olarak alınan ve içerisinde findıkkabuğu külü bulunmayan FKK0 hamurunun çaprazbağ yoğunluğu $70,13 \times 10^{3} \mathrm{~mol} / \mathrm{cm}^{3}$ 'tür. Buna göre, \% 20 oranında findıkkabuğu eklenmesiyle elde edilen FFK20 bileşiğinin çaprazbağ yoğunluğu yaklaşık iki kat arttığ1 görülmüştür.

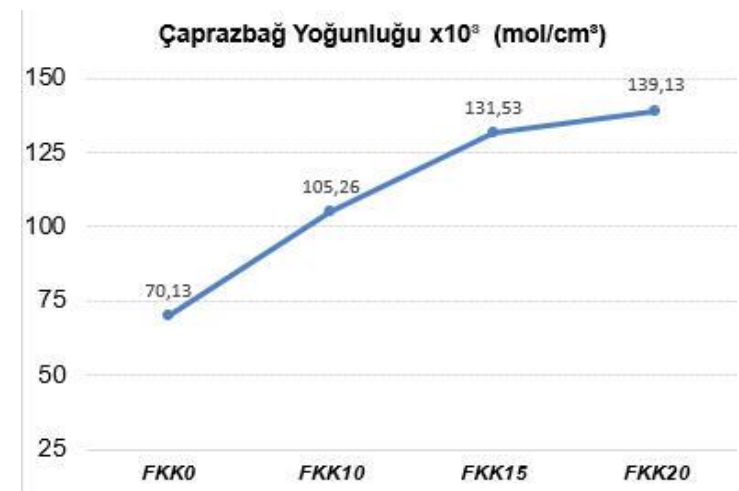

Şekil 1. Bileşiklerin çapraz bağ yoğunluk değişimleri

Yoğunluk ve sertlik test sonuçları incelendiğinde artan findıkkabuğu kül içeriğine bağlı olarak bileşiklerin yoğunluklarının ve sertliklerinin arttığı görülmüştür. FFK0 bileşiğinin yoğunluğu $1.24 \mathrm{~g} / \mathrm{cm}^{3}$ 'tür. En yüksek yoğunluk FFK20 bileşiğine $\left(1,36 \mathrm{~g} / \mathrm{cm}^{3}\right)$ ait olmasına rağmen ayakkabı kauçuk tabanlarına uygulanan, ISO 2781 standartlarına göre yoğunluğun max. $1,5 \mathrm{~g} / \mathrm{cm}^{3}$ olması gerektiği bilinmektedir. Buna dayanarak üretilen yeni bileşiklerin yoğunlukları standarda göre uygun olduğu görülmüştür (Şekil 2).

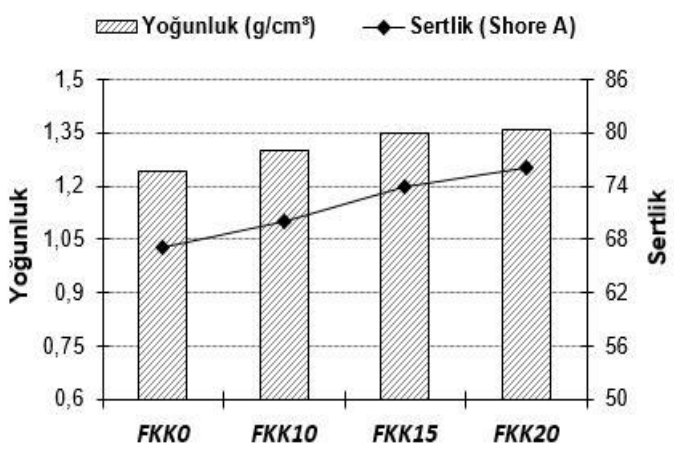

Şekil 2. Bileşiklerin yoğunluk ve sertlik değişimleri

Karbürize edilmiş findıkkabuğu ilave edilmeyen FKK0 bileşiğinin sertlik değeri 67 Shore A iken \% 10 karbürize edilmiş findıkkabuğu külü ilave edilen FKK10 bileşiğinde bu değer 70 Shore A'dır. FKK0 bileşiğine göre sertlik değeri \% 4,47 oranında artmıştır. FKK15 ve FKK20 bileşiklerinde ise sertlik değerleri FKK0 bileşiğine göre sırasıyla \% 10,44 ve \% 13,44 oranında arttığı görülmüştür. Sertlik artışının sebebi bileşiklerin çaprazbağ 
yoğunluklarındaki artıştan kaynaklandığı düşünülmektedir. Nabil ve arkadaşlarının yapmış olduğu bir çalışmada çapraz bağ yoğunluğu arttıkça numunenin sertliklerinin ve \% birim uzama (kopma uzama) değerinin artacağını rapor edilmiştir [23]. Şekil 3 incelendiğinde artan Fındıkkabuğu külünün \% birim uzama değerini arttığı görülmüştür dolayısıyla bu çalışma Nabil ve arkadaşlarının ortaya koyduğu sonuçları doğrular niteliktedir. En yüksek \% birim uzama FKK20 bileşiğinde elde edilmiştir. FKK0 bileşiğinin \% birim uzaması \% 323 iken FKK ilave edilen hamurlarda bu değerin \% 387- 411 arasında değiştiği Şekil 3’te görülmektedir.

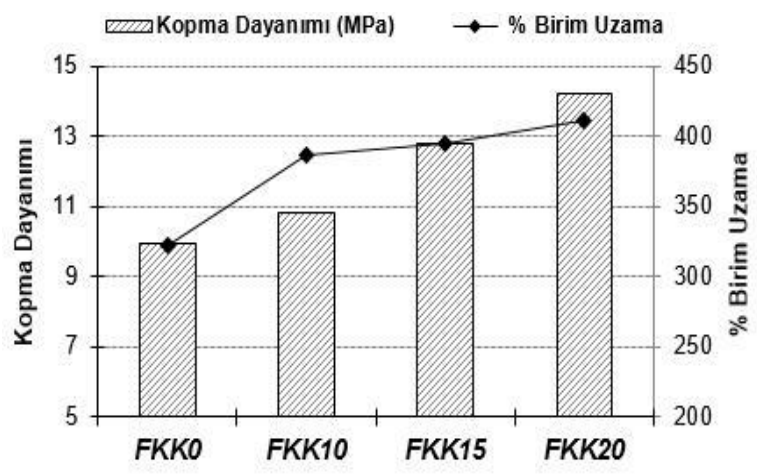

Şekil 3. Bileşiklerin kopma dayanımları ve \% uzama değişimileri

Şekil 3 incelendiğinde bileşiklere ilave edilen FKK oranı arttıkça bileşiklerin kopma dayanımlarında artış olduğu gözlemlenmiştir. Kauçuk hamuruna ilave edilen dolgu maddelerinde potansiyel fiziksel etkileşimler, dağılımın yeterli olduğu durumda yüksek kauçuk-dolgu arayüzeyini güçlendirir. Artan çaprazbağ yoğunluğunun da katkısıyla, bu hamurdan elde edilen bileşiklerin kopma dayanımı, kopma uzaması ve yırtılma dayanımı özelliklerinin geliştiği bilinmektedir [24,25]. Bu çalışmada da artan FKK oranı kauçuk-dolgu arayüzey etkileşimini arttırdığı ve bu durumun mekanik özellikleri iyileştiği düşünülmektedir.

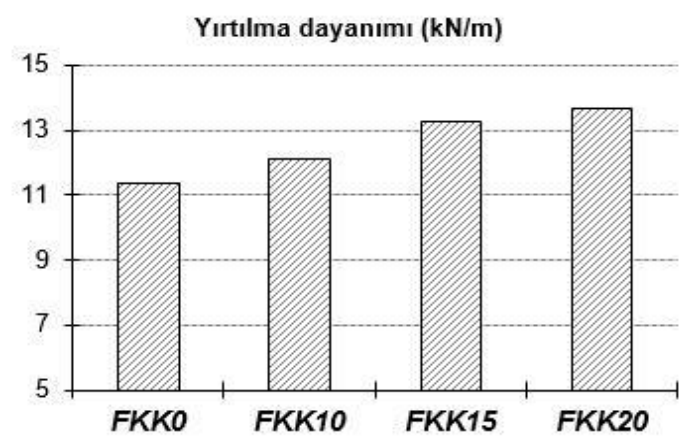

Şekil 4. Bileşiklerin yırtılma dayanım değişsimleri

Şekil 4'de FKK ilave oranı artıkça bileşiklerin yırtılma dayanımlarının sistematik olarak arttığı gözlemlenmiştir. ISO 34 standardına göre yapılan yırtılma deney sonuçlarında FKK0 bileşiğinin yırtılama dayanımı 11,34 kN/m iken \% 20 oranında FKK ilavesi ile bileşiğin yırtılma dayanımının 13,66 kN/m'ye yükseldiği görülmüştür. Diğer bileşiklerin yırtılma dayanımları sırası ile FKK10 bileşiğinde 12,11 kN/m, FKK15'te ise 13,26 $\mathrm{kN} / \mathrm{m}$ 'dir elde edilen test sonuçları ISO 5676 standardıyla karşılaştırıldığında tüm bileşiklerin yırtılma dayanımlarının belirtilen standartta istenilen $6 \mathrm{kN} / \mathrm{m}$ den daha yüksek olduğu tespit edilmiştir. Bileşiklerin yırtılma dayanımlarının, kullanılan dolgu miktarına ve dolgu çeşidine göre, değişiklik göstereceği bilinmektedir [26,27]. 


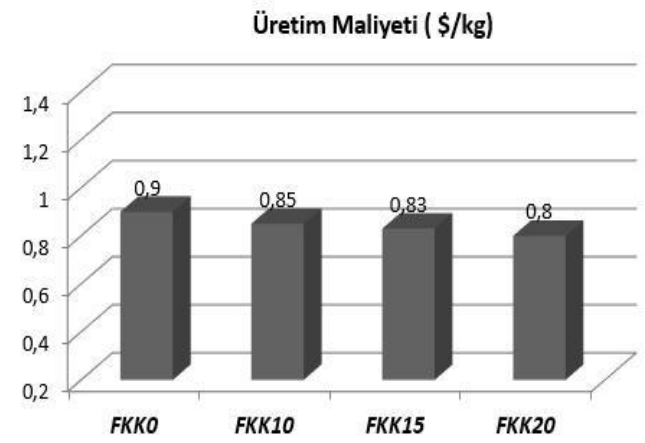

Şekil 5. Bileşiklerin üretim maliyeti değişimleri

Şekil 5. incelendiğinde üretim maliyetinin kg fiyatları verilmiştir. Kauçuk matrisli bileşiklerde kullanılan dolgu malzemelerine bağlı olarak, dolgu miktarı artıkça maliyetinin düştüğü görülmüştür. FFK ilave edilmeyen bileşiğin üretim maliyeti $0,9 \$ / \mathrm{kg}$ iken FKK20 bileşiğinin üretim maliyetinin $0,8 \$ / \mathrm{kg}$ olduğu hesaplanmıştır. Aradaki fark 0,1 \$/kg' dır. Kg fiyatında büyük bir fark yok gibi görünse bile, 1 tonda 100 \$' a kadar büyük bir avantaj sağladığı görülmüştür. Fındık kabuklarının her hangi bir ticari değerinin olmaması, nakliye ve fındık üreticisine herhangi bir ödeme yapılmadığından maliyet hesabında bu durum göz ardı edilmiştir. Karbürize edilmiş fındık kabuğu küllerinin dolgu olarak kullanıldığında mekanik özelikleri artırmasının yanında üretim maliyetini düşürmesi diğer dolgulara nazaran findık kabuğu külünü cazip duruma getirmiştir. Bu çalışma ayakkabı tabanı üretimi yapan özellikle küçük çaplı işletmelerin birbirleriyle fiyat ve kalite yönünden rekabet edebilecekleri bir çözüm sunulmuştur.
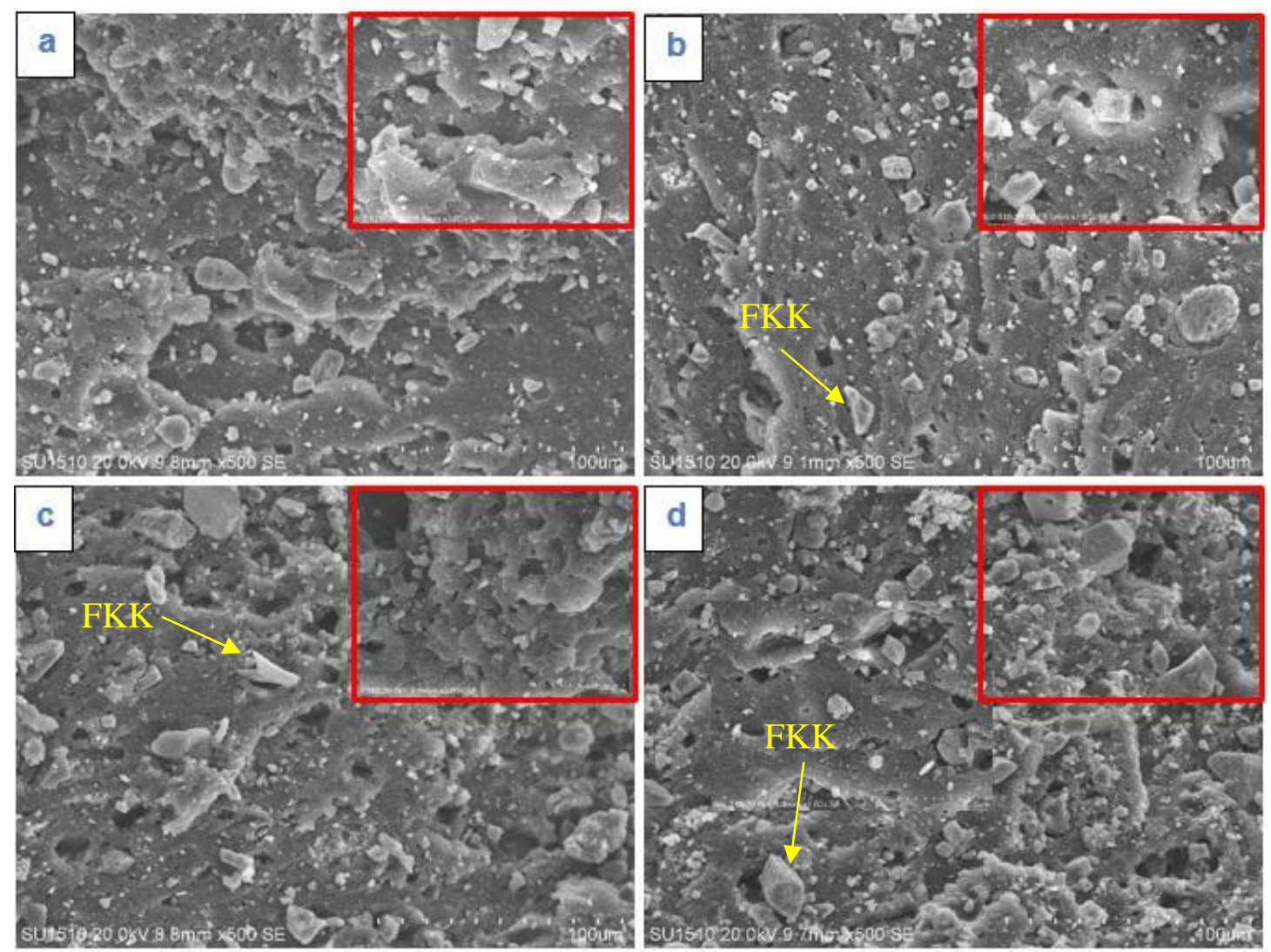

Şekil 6. Bileşiklerin kopma yüzeylerinin SEM görüntüleri, a) FKKO, b) FKK10, c) FKK15 ve d) FKK20

FKK0 bileşiğine 10, 15 ve \% 20 oranında karbürize edilmiş fındık kabuğu külü ilave edilerek elde edilen FKK10, FKK15 ve FKK20 bileşiklerinin, çekme testleri sonrasındaki kopma yüzeylerinin SEM görüntüleri Şekil 6'da verilmiştir. Deneysel çalışmada kullanılan numunelerinin kopma yüzeylerinden alınan SEM görüntüleri 
incelendiğinde, dolgu miktarı artıkça, bileşiğin içerisindeki dolguların daha belirgin hale geldiği görülmektedir. SEM görüntülerinde, bileşiklere ilave edilen FKK oranın artması ile birlikte bileşiklerin içerisindeki dolgularının homojenliğinde azalma olduğu ve matris içerisindeki dolgu dağılımlarına bakıldığında, dolgular arasındaki mesafenin azaldığı, hatta toparlanarak bir araya geldiği görülmektedir. Aynı zamanda FKK dolgusunun sürekliliği artırdığı hem SEM görüntülerinden hem de \% birim uzama test sonuçlarından anlaşılmaktadır.

\section{SONUÇLAR}

Bu çalışma NBR 1502 matrisli kauçuk bileșiklerine karbürüze edilmiş findık kabuğu külünün çapraz bağ yoğunluğuna ve mekanik özelliklere etkisini incelemiş̧ir. Burada sunulan sonuçlar, karbürize edilmiş findık kabuğu kül dolgusunun mekanik özellikleri geliştirici ve çapraz bağ sayısını arttırıcı rol üslendiğini göstermiş̧ir. Bunun yanında kauçuk tabanlarda sıklıkla kullanılan, karbon siyahı ve kalsit gibi dolgulara alternatif bir dolgu olduğu yapılan tesler neticesinde ortaya konulmuştur. Mekanik özeliklerin ve çapraz bağ yoğunluğunun, dolgu miktarı ile dolgu malzemesinin morfolojisine ve dolgu maddesi-kauçuk ara yüz etkileşmesine bağlı olduğu gösterilmiş̧tir. Elde edilen tüm test sonuçları doğrultusunda karbürüze edilmiş fındık kabuğu külünün NBR 1502 matrisli kauçuk bileşiklerinde ikincil dolgu olarak kullanılabileceği ispatlanmıştır.

\section{KAYNAKLAR}

[1] Akçakale, N. (2008) Investigation of the Effect of Some Additives on the Mechanical Properties of NR/SBR Elastomer Based Sole Materials, Turkey: Sakarya University, Having Satıfactorily Completed all Requirements of the Department of, Philosopher of Doctorate Thesis, 29-30.

[2] Akçakale,N. \& Bülbül, Ş. (2017). The effect of mica powder and wollastonit fillings on the mechanical properties of NR/SBR type elastomer compounds. J. Rubb. Res., 20 (3), 157-167.

[3] Furtado, C.R.G. Leblanc, J.L. \& Nunes, R.C.R. (1999) Fatigue resistance of mica-carbon black styrene butadiene rubber (SBR) compounds. Eur. Polymer J., 35,1319-1325.

[4] Furtado, C.R.G. Leblanc, J.L. \& Nunes, R.C.R. (2000). Mica as additional filler in SBR-silica compounds. Eur. Polymer J., 36, 1717-1723.

[5] De, D. Panda, P.K. Roy, M. \& Bhunia, S. (2013). Reinforcing effect of reclaim rubber on natural Rubber/Polybutadiene Rubber blends. Materials and Design, 46, 142-150.

[6] Malas, A. Pal, P. \& Das, C.K. (2014). Effect of expanded graphite and modified graphite flakes an the physical and thermo-mechanical properties of Styrene Butadiene Rubber/Polybutadiene Rubber (SBR/BR) blends. Materials and Design, 55, 664-673.

[7] Mohan, T.P. Kuriakose, J. \& Kanny, K. (2012). Water up take and mechanical properties of Natural RubberStyrene Butadine Rubber (NR-SBR) - nanoclay Composites. J. of Industrial and Engineering Chemistry, 18, 979-985.

[8] Bülbül, Ş. Yaşar, M. \& Akçakale, N. (2014). Effect of changing of filling materials in NR-SBR type elastomer based rubber materials on mechanical properties. Polymer (Korea), 38(5), 664-670.

[9] Saramolee, P. Sahakaro, K. Lopattananon, N. Dierkes, W.K. \& Noordermeer, J.W.M. (2016). Compatibilisation of silica-filled natural rubber compounds by functionalised low molecular weight polymer. J. of Rubber Research, 19(1), 28-42.

[10] Alfaro, E.F. Dias, D.B. \& Silva, L.G.A. (2013). The study of ionizing radiation effects on polypropylene and rice husk ash composite. Radiation Physics and Chemistry, 84, 163-165.

[11] Kim, S.M. \& Kim, K.J. (2013). Effects of accelerators on the vulcanization properties of silica vs. carbon black filled natural rubber compounds. Polymer (Korea), 37(3), 269-275.

[12] Ge, X. Le, M.C. \& Cho, U.R. (2014). Fabrication of EPDM Rubber/organo-bentonite composites, influence of hydrochloric acid on the characteristics of modified bentonite and final products, Polymer (Korea), 38(1) $62-68$. 
[13] Prasertsri, S. Lagarde, F. Rattanasom, N. Sirisinha, C. \& Daniel, P. (2013). Raman spectroscopy and thermal analysis of gum and silica-filled NR/SBR blends prepared from latex system. Polymer Testing, 32, 852-861.

[14] Furtado C .R.G., Leblanc, J.L. \& Nunes, R.C.R. (2000). Mica as additional filler in SBR-Silica compounds. Eur. Polym. J., 36, 1717-1723.

[15] Yan,G. Junchi, Z. Xin, Y. Dongli, H. Meimei, X. \& Liqun, Z. (2016). Preparation and performance of Silica/SBR master batches with high silica loading by latex compounding method. Composites Part B, 85, $130-139$.

[16] Wang, X. Hengyi, L. Guangsu, H. Li-Heng, C. \& Jinrong, W. (2017). Graphene oxide induced crosslinking and reinforcement of elastomers. Composites Science and Technology, 144, 223-229.

[17] Bülbül Ş. \& Büyük S.S. (2018) The effect of walnut shell ash fillings on the mechanical properties of SBR type rubber compounds. 5th International Symposium on Multidisciplinary Studies. 16-17 Kasim, Ankara 457.

[18] Akcakale, N. (2017). Effects of carburized rice husk powders on physical properties of elastomer based materials. KGK-Kautschuk Gummi Kunststoffe, 4093, 49-54.

[19] Ghari, H.S. \& Jalali-Arani, A. Nanocomposites based on natural rubber, organoclay and nano-calcium carbonate: Study on the structure, cure behavior, static and dynamic-mechanical properties. Applied Clay Science 119 (2016) 348-357.

[20] Balat, M. (2005) Use of Biomass Sources for Energy in Turkey and a View to Biomass Potential. Biomass and Bioenergy, 29, 32-41.

[21] Croll, S.G. (2010). Application of the Flory-Rehner equation and the griffith fracture criterion to paint stripping, Journal of Coating Technology Research, 7(1), 49-55.

[22] Flegler, S.L. Heckman, J.W. \& Klomparens, K.L. (1993). Scanning and transmission electron microscopy. England: Oxford University Press, ISBN 0-19-510751-9,

[23] Nabil,H. Ismail, H. \& Ratnam, C.T. (2014). Simultaneous enhancement of mechanical anddynamic mechanical properties of natural rubber/recycled ethylene-propylene-dienerubber blends by electron beam irradiation. Int. J. Polym. Anal. Charact, 19(3), 272-285.

[24] Rao V. \& Johns, J. (2008). Mechanical properties of thermoplastic elastomeric blends of chitosan and natural rubber latex. J. Appl. Polym. Sci., 107(4), 2217-2223.

[25] El-Nashar, D.E. Ahmed, N.M. \& Yehia, A.A., (2012). The role of ion-exchange bentonites in changing the properties of styrene-butadiene rubber composites. Materials and Design, 34, 137-142.

[26] Findik, F. Yilmaz, R. \& Koksal, T. (2004). Investigation of mechanical and physical properties of several industrial rubbers. Materials and Design, 25(4), 269-276.

[27] Bülbül, Ş. \& Akçakale, N. (2019). The Production and mechanical properties of carburized corn cob ash added rubber compounds. KGK-Kautschuk Gummi Kunststoffe, 72(4/19), 30-35. 